\title{
A Novel Technique to Detect EGFR Mutations in Lung Cancer
}

\author{
Yuanbin Liu ${ }^{1,2, \dagger}$, Ting Lei ${ }^{3, \dagger}$, Zhiyu Liu ${ }^{4,+}$, Yanbin Kuang ${ }^{1}$, Jianxin Lyu ${ }^{2, *}$ and Qi Wang ${ }^{1, *}$ \\ 1 Department of Respiratory Medicine, the Second Hospital, Dalian Medical University, Dalian 116023, China; \\ ybliu_301@163.com (Y.L.); kybkyb2@163.com (Y.K.) \\ 2 Key Laboratory of Laboratory Medicine, Ministry of Education, Zhejiang Provincial Key Laboratory of \\ Medical Genetics, Wenzhou Medical University, Wenzhou 325035, China \\ 3 Department of Thoracic Surgery, the Second Hospital of Dalian Medical University, Dalian 116023, China; \\ leiting0612@sina.com \\ 4 Department of Urinary Surgery, the Second Hospital, Dalian Medical University, Dalian 116023, China; \\ letter89@163.com \\ * Correspondence: jxlu313@163.com (J.L.); wqdlmu@163.com (Q.W.); Tel.: +86-577-8668-9805 (J.L.); \\ +86-411-8467-1291 (Q.W.) \\ + These authors contributed equally to this work.
}

Academic Editor: William Chi-shing Cho

Received: 30 March 2016; Accepted: 18 May 2016; Published: 23 May 2016

\begin{abstract}
Epidermal growth factor receptor (EGFR) gene mutations occur in multiple human cancers; therefore, the detection of EGFR mutations could lead to early cancer diagnosis. This study describes a novel EGFR mutation detection technique. Compared to direct DNA sequencing detection methods, this method is based on allele-specific amplification (ASA), recombinase polymerase amplification (RPA), peptide nucleic acid (PNA), and SYBR Green I (SYBR), referred to as the AS-RPA-PNA-SYBR (ARPS) system. The principle of this technique is based on three continuous steps: ASA or ASA combined with PNA to prevent non-target sequence amplification (even single nucleotide polymorphisms, SNPs), the rapid amplification advantage of RPA, and appropriate SYBR Green I detection (the samples harboring EGFR mutations show a green signal). Using this method, the EGFR 19Del(2) mutation was detected in $5 \mathrm{~min}$, while the EGFR L858R mutation was detected in $10 \mathrm{~min}$. In this study, the detection of EGFR mutations in clinical samples using the ARPS system was compatible with that determined by polymerase chain reaction (PCR) and DNA sequencing methods. Thus, this newly developed methodology that uses the ARPS system with appropriate primer sets is a rapid, reliable, and practical way to assess EGFR mutations in clinical samples.
\end{abstract}

Keywords: RPA; ASA; SYBR; EGFR mutation; novel methodology; point-of-care test (POCT)

\section{Introduction}

Epidermal growth factor receptor (EGFR), a member of tyrosine kinase receptors, plays an important role in the regulation of cell proliferation, survival, and differentiation [1]. Upon ligand binding, as is the case with the epidermal growth factor (EGF), EGFR will form dimers to autophosphorylate the cytoplasmic tyrosine kinase domains and activate the EGFR signaling pathway [2]. Previous studies have shown that EGFR is overexpressed in a number of solid tumors, such as lung, breast, prostate, bladder, colon, head and neck, and ovarian carcinomas [3]. In non-small cell lung cancer (NSCLC), EGFR is overexpressed due to EGFR amplification or mutation [4-6]. In EGFR kinase domain mutations, 19Del(E746-A750) and L858R (the most prevalent mutations) account for nearly $90 \%$ of the EGFR mutations in NSCLC [7]. Patients with EGFR-mutated NSCLC have shown clinical responses to the orally administered EGFR inhibitor gefitinib, leading to a new 
era of the targeted therapy of human cancer [4-6]. Indeed, previous in vitro experiments have demonstrated that specific EGFR mutants have increased tyrosine kinase activity and possess a higher sensitivity to growth inhibition by tyrosine kinase inhibitors [8]. Thus, detection of EGFR mutations has become an important diagnostic procedure. To date, polymerase chain reaction (PCR) amplification of tumor specimens plus DNA sequencing has become a standard technique. Nevertheless, the molecular diagnosis methodology still greatly impedes this effect and remains a major obstacle for successful targeted therapy [9] because this technique requires sophisticated equipment and complex experimental procedures [10-13], including thermal cycling equipment and a DNA sequencer. Currently, an isothermal enzymatic DNA amplification system that includes nucleic acid sequence-based amplification [14], loop-mediated isothermal amplification (LAMP) [15], rolling circle amplification [16] and helicase-dependent amplification is commonly used [17]. Recently, the smart-amplification process method $[18,19]$ has been developed to detect EGFR mutations, but the complex primer design, large equipment, and professional operators are disadvantages. In contrast, recombinase polymerase amplification (RPA) is a more advanced DNA-amplification method with a reaction temperature of $37^{\circ} \mathrm{C}$, easy primer design, and rapid amplification speed [20], yielding a large amount of product [21]. Moreover, the role of strand-exchange assisted by ATP hydrolysis is an interesting and useful method for gene amplification/detection. RPA can be applied to detect different DNA and RNA [22,23], but so far, it has not been used to detect human gene mutations.

Thus, in this study, we described a novel method based on allele-specific amplification (ASA), RPA, peptide nucleic acid (PNA), and SYBR Green I, which is called the AS-RPA-PNA-SYBR (ARPS) system, to identify EGFR mutations. This method could be used for the diagnosis of EGFR mutations and for the identification of patients suitable for targeted therapy. ASA/AS theory [24], RPA, PNA, and SYBR Green I were utilized in this system without any large equipment, sophisticated design of fluorescence-probe/primers, or lateral flow strips. The basis of this technology is to amplify mutated genomic DNA with the PNA technology specifically by inhibition of non-target sample amplification. After that, the recombinase polymerase-amplified products will generate fluorescence with SYBR Green I in order to visualize the mutant gene products. We anticipated that this method would be a reliable and cost-efficient method for the future screening of EGFR mutations that is consistent with Precision Medical development aspirations [25].

\section{Results}

\subsection{Detection of EGFR Mutations in NSCLC Cell Lines and Comparison of Gold Standard PCR and Direct} DNA Sequencing with Our Novel Detection Technique

In this study, we detected EGFR mutations in cell lines using PCR and the direct DNA sequencing technique, and the data confirmed EGFR mutations in these NSCLC cell lines that matched with the ATCC cell line characteristics, i.e., HCC-827 cells had an acquired EGFR mutation at the tyrosine kinase domain (E746-A750 deletion), while H-1975 cells harbored the heterozygous EGFR L858R mutation. In contrast, the A-549 cell line did not have any EGFR mutations.

Next, we performed our novel technique to assess EGFR mutations in these cell lines and obtained similar results as the PCR and direct DNA sequencing data (Figures 1 and 2).

\subsection{Sensitivity of ARPS in Mixed-DNAs to Detect EGFR Mutations}

Tumor samples are frequently composed of numerous subpopulations of cancer cells. In addition to accurate puncture and sample extraction, detection of EGFR mutations must be capable of catching mutations in heterogeneous DNA samples. To test ARPS for this capability, we extracted genomic DNA from known EGFR-mutated tumor cell lines mixed with increasing amounts of wild-type DNA (the total amount of DNA was $300 \mathrm{ng}$ ) to assess the sensitivity of our method. In the serial dilution experiments with DNA samples from HCC-827, H-1975, and A549 cell lines, ARPS detected the EGFR 
19Del(2) mutation and the EGFR L858R mutation with $30 \%$ and $40 \%$ of known EGFR-mutated genomic DNA samples, respectively, in 15 min (Figure 3).

\section{A.}
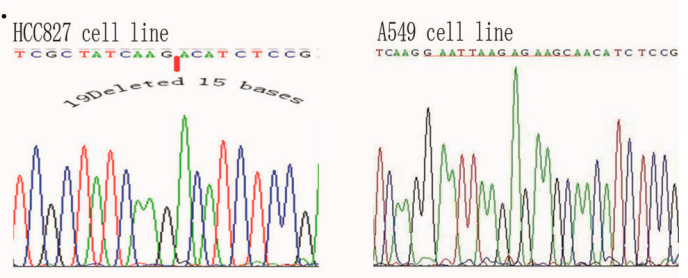

B.

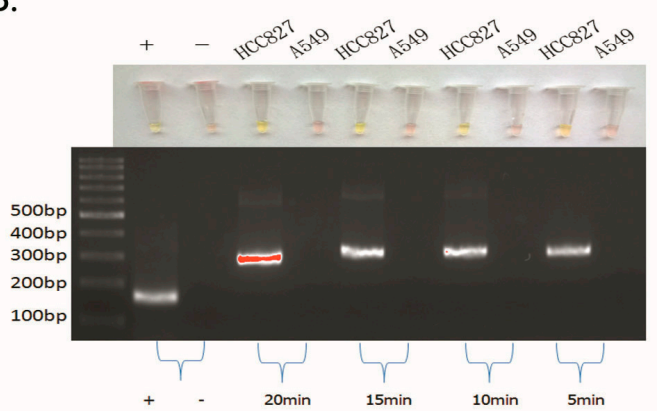

Figure 1. Comparison of the polymerase chain reaction (PCR) and DNA sequencing data with our visualization data using the ARPS method for detection of the epidermal growth factor receptor (EGFR)19Del(2) mutation in non-small cell lung cancer (NSCLC) cells. (A) The PCR and DNA sequencing data; (B) The specificity and timely sensitivity of the AS-RPA-PNA-SYBR (ARPS) method for detection of the EGFR 19Del(2) mutation. The " +" was the positive control in the recombinase polymerase amplification (RPA) reaction kit (143 bp in size), which was detected between 5 and $20 \mathrm{~min}$. The mutated EGFR 19Del(2) band was $266 \mathrm{bp}$, and $300 \mathrm{ng}$ of the DNA template was used. Results of ARPS were negative in red, positive in green.

A.

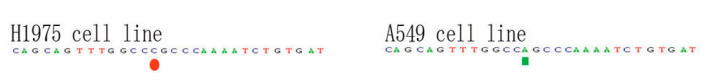

B.
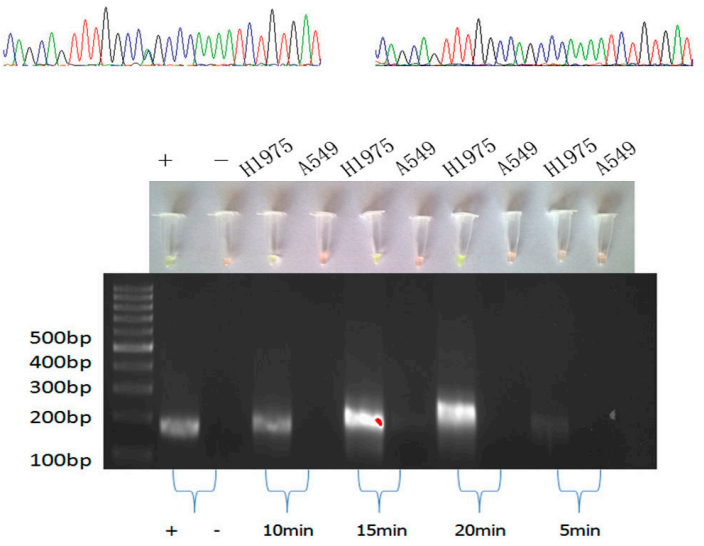

Figure 2. Comparison of the PCR and DNA sequencing data with our visualization data using the ARPS method to detect the EGFR L858R mutation in NSCLC cells. (A) The PCR and DNA sequencing data; (B) The specificity and timely sensitivity of the ARPS method for detection of the EGFR L858R mutation. The " + " was the positive control in the RPA reaction kit (143 bp in size), which was detected between 10 and $20 \mathrm{~min}$. The target mutated band size was $201 \mathrm{bp}$, and $300 \mathrm{ng}$ of the DNA template was used. Results of ARPS were negative in red, positive in green. 


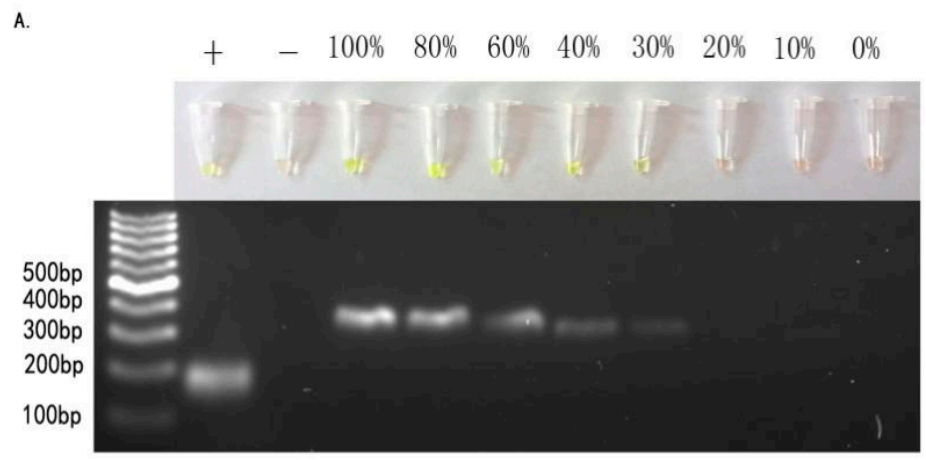

B.

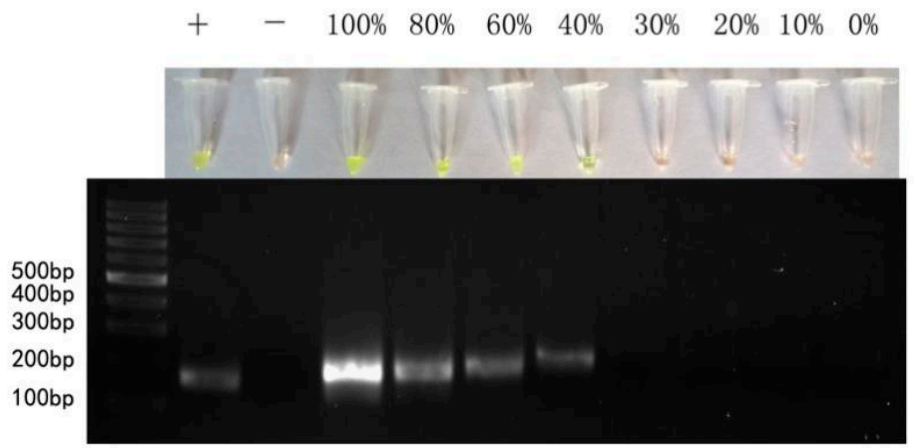

Figure 3. Sensitivity of the ARPS technique. (A) ARPS reaction using 19 Del(2) mutation-specific primers with serial dilutions of genomic DNA isolated from HCC-827 cells; (B) ARPS reaction using L858R point mutation-specific primers with serial dilutions of genomic DNA from H-1975 cells. Results of ARPS were negative in red, positive in green.

2.3. Detection of EGFR Mutations in NSCLC Tissue Samples Using our Novel ARPS Method vs. the PCR and DNA Sequencing Method

To further assess the EGFR mutations in the NSCLC tissue specimens, we collected 46 cases of NSCLC. Three cases were diagnosed with the EGFR L858R mutation and one with the EGFR 19Del(2) mutation using the amplification refractory mutation system (ARMS) in our hospital, and we reconfirmed these four mutated and two non-mutated samples in EGFR samples using the PCR and DNA sequencing method (Figure 4).

We then assessed the EGFR mutations in these six tissue samples using our novel method and found that after a 15-min amplification, we could mix SYBR in the cap and visualize the results (Figure 4), which were consistent with the PCR and DNA sequencing data.

\subsection{Specific Considerations While Performing the ARPS Assay to Detect EGFR Mutations}

We first designed the specific ARPS primers to detect the EGFR 19Del(2) and L858R mutations (Table 1). However, in the selected set of EGFR L858R primers without the use of PNA, the agarose gel electrophoresis analysis showed very low specificity (Figure S1). The specificity was not improved even after the addition of the other base mismatched at the $3^{\prime}$-end of the reverse primers (Table 1 and Figure 5). The selected set of primers without mismatch fully corresponded to the mutated DNA sequences in the RPA experiment (Figures 1-3). Moreover, the ethanol method received a satisfactory result with correct band positions, although our three trials of the column purification method failed. 
A.

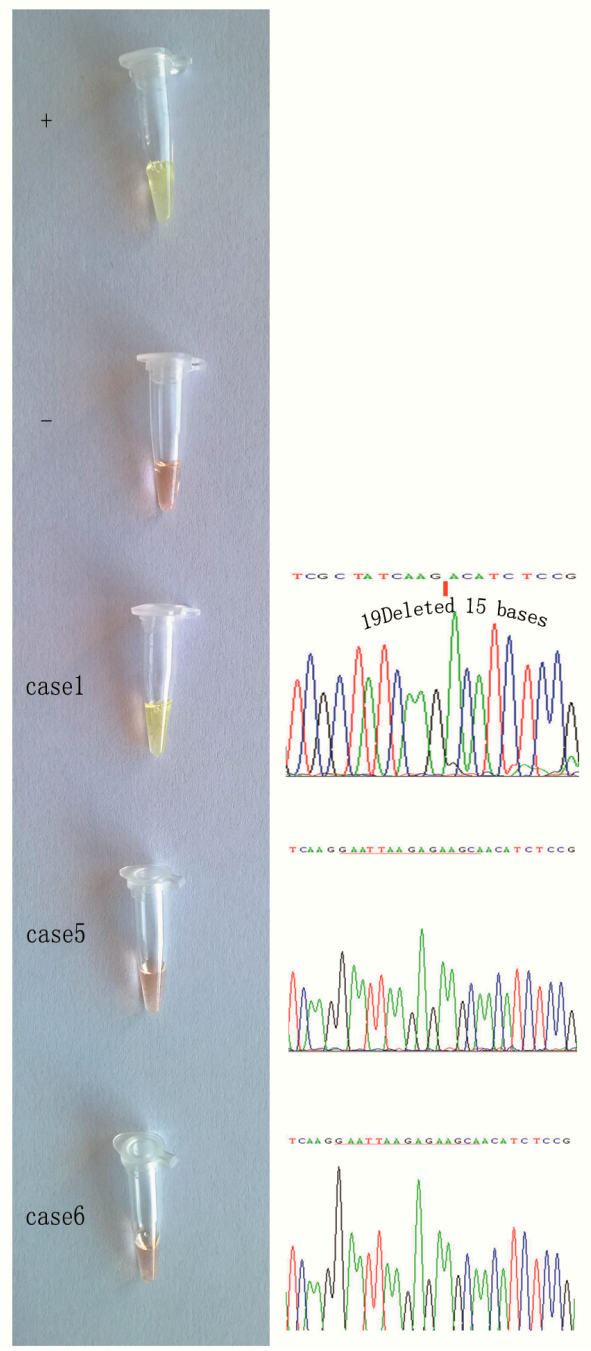

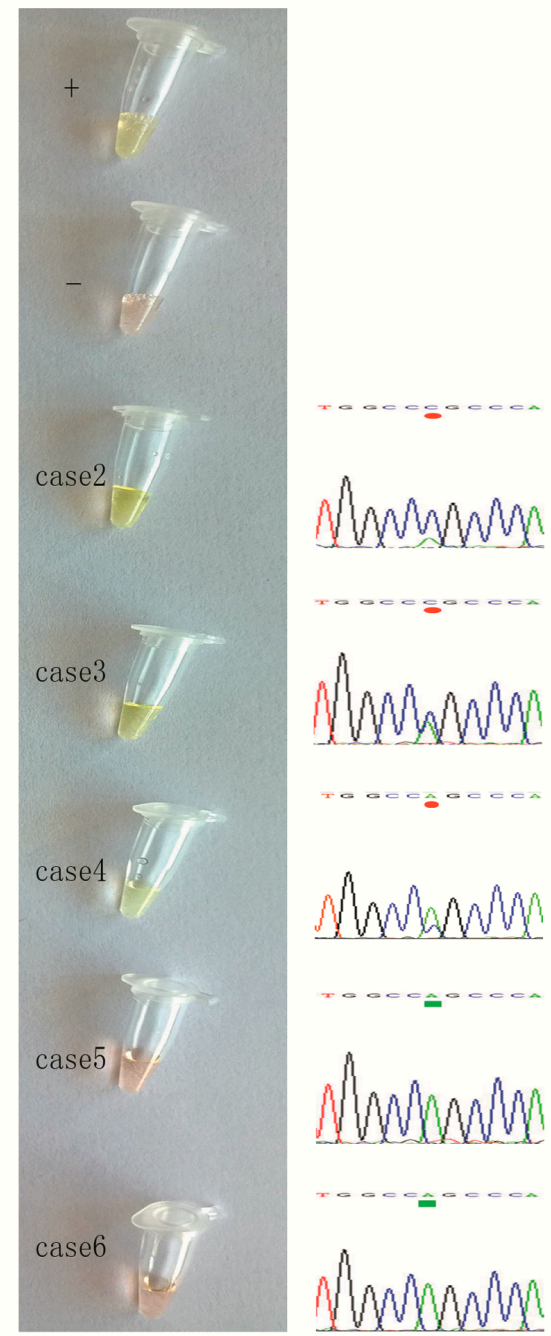

Figure 4. Comparison of the PCR and DNA sequencing data with our visualization data using the ARPS method to detect the EGFR mutation in NSCLC tissue specimens. (A) EGFR 19Del(2) mutation. The left panel shows our data, and the right panel shows the DNA sequencing data. From top to bottom, the quality control of the positive sample, the quality control of the negative sample (HCC-827 and A549 cell lines), one positive clinical tissue sample, and two negative clinical tissue samples are shown; (B) The EGFR L858R mutation. The left panel shows our data, and the right panel shows the DNA sequencing data. From top to bottom, the quality control of the positive sample, the quality control of the negative sample (H-1975 and A549 cell lines), three positive clinical tissue samples, and two negative clinical tissue samples are shown. Results of ARPS were negative in red, positive in green.

Table 1. RPA primers used to detect EGFR 19Del(2) and L858R mutations.

\begin{tabular}{l}
$\frac{c}{\text { EGFR Mutation Type Primers Amplicon (bp) }}$ \\
\hline 19Del(2)FP 5'-GTGAGAAAGTTAAAATTCCCGTCGCTATCAAGACATCTC-3' 266 \\
19Del(2)RP 5'-GATACCAGCATGGGAGAGGCCAGTGCTGTCTCTAAG-3' \\
L858R FP 5'-CTGAATTCGGATGCAGAGCTTCTTCCCATGA-3' 201 \\
L858R RP 5'-CTTTCTCTTCCGCACCCAGCAGTTTGGCCC-3' \\
PNA 5'-GCCAGCCCAA-3' \\
\hline
\end{tabular}

FP, Forward Primer; RP, Reverse Primer; PNA, peptide nucleic acid. 
A.
CTTTCTCTTCCGCACCCAGCAGTTTGGCCC
CTTTCTCTTCCGCACCCAGCAGTTTGGTCC
CTTTCTCTTCCGCACCCAGCAGTTTGGACC
CTTTCTCTTCCGCACCCAGCAGTTTGGGCC

B.

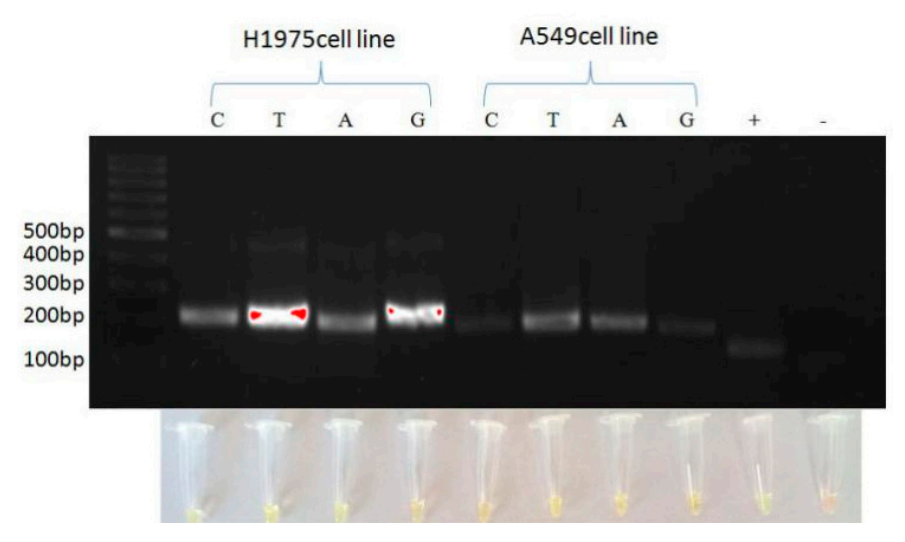

Figure 5. Primer sequences and agarose gel electrophoresis data. (A) The position of another mismatch base in the reverse primer (green letters) to detect EGFR L858R; (mutant base in red letter) (B) The agarose gel electrophoresis and ARPS results of the different mismatch bases. The band size was 201 bp, and the "+" indicates the positive control from the RPA reaction kit (143 bp). The amount of DNA used was $300 \mathrm{ng}$.

Furthermore, SYBR was really sensitive at detecting double-stranded DNA, and the minimum detection limit was 20 pg of double-stranded DNA under 254-nm ultraviolet (UV) light. However, the use of UV light should be avoided with this method because both positive and negative results will show fluorescent green. Moreover, the amount of DNA sample should be less than $2 \mu \mathrm{g}$, and $2 \mu \mathrm{L}$ of $10 \mathrm{mM}$ each primer should be used; otherwise, the experimental results cannot be visualized by the naked eye. Thus, in our optimized SYBR detection system (Figure S2), the template of genomic DNA was $300 \mathrm{ng}$ with $2 \mu \mathrm{L}$ of each primer $(10 \mathrm{mM})$ and $1 \mu \mathrm{L}$ of $200 \times$ SYBR per $20 \mu \mathrm{L}$ of RPA product.

As for the specificity and timely sensitivity of the ARPS method at detecting the EGFR 19Del(2) mutation (deletion of 15 base pairs), the identification of specific DNA fragments was achieved by this method from 5 to $20 \mathrm{~min}$, and the ARPS results were consistent with the sequencing results (Figure 1A). After the RPA reactions were complete, $30 \mu \mathrm{L}$ of the product was transferred into a new 1.5-mL Eppendorf tube, and $1 \mu \mathrm{L}$ of $200 \times$ SYBR was added to the former tube within $1 \mathrm{~min}$. In addition, we purified the $30 \mu \mathrm{L}$ of product using our ethanol method and performed agarose gel electrophoresis to confirm the band position (Figure 1B). When the ARPS reaction reached more than $40 \mathrm{~min}$, a false-positive band appeared.

To detect the EGFR L858R mutation, we used the selected set of primers and obtained specific DNA fragments between 10 and $20 \mathrm{~min}$, as shown by electrophoresis (Figure 2).

\section{Discussion}

In the current study, we developed the ARPS method to detect EGFR mutations with two sets of specifically designed primers capable of recognizing a 15-bp deletion of EGFR and an EGFR SNP-type mutation in both NSCLC cell lines and tissue samples. We were able to successfully assess the EGFR 19Del(2) mutation in $5 \mathrm{~min}$ and the EGFR L858R mutation in $10 \mathrm{~min}$ in NSCLC cell lines with the naked eye. Moreover, we also successfully detected these mutations in NSCLC tissue samples. Compared to 
the PCR and DNA sequencing method, our newly developed ARPS method apparently has several advantages, including a shorter analysis time, low cost, and more convenient method, over the conventional DNA sequencing method. In addition, ARPS allows us to detect EGFR mutations in 30\% to $40 \%$ of targeted mutant alleles in genomic DNA samples without any background amplification, which is similar to or better than DNA sequencing.

While performing this assay, we utilized the SYBR-assisted detection method and determined the appropriate SYBR concentration to be $1 \mu \mathrm{L}$ of $200 \times$ SYBR per $20 \mu \mathrm{L}$ of RPA product. Meanwhile, we set the appropriate amount of DNA template to $300 \mathrm{ng}$ because too much DNA template would jeopardize the SYBR detection and too little would also affect sensitivity and produce primer-dimers. After the RPA reaction, mixing SYBR in the cap resulted in the feasibility of SYBR Green I detection [26]. Furthermore, the ethanol method was more efficient and convenient to purify the RPA products for electrophoresis. In contrast, using the column method, DNA could not be isolated according to the manufacturer's protocol of the EasyPure ${ }^{\circledR}$ PCR Purification Kit (TransGen Biotech, Beijing, China). We speculate that this may be because the DNA-protein complex in the reaction could not adsorb to the adsorption column or because the complex could not elute from the column. So, either collection of the eluted liquid from the bottom tube (as suggested by the manufacturer) or the addition of preheated solution EB (triple-distilled water) into the column for $1 \mathrm{~min}$ was not able to recover DNA for agarose gel electrophoresis.

Furthermore, to detect the 15-bp deletion of EGFR, we utilized both SYBR detection and electrophoresis to obtain visible bands, with an absolute accuracy between 5 and $20 \mathrm{~min}$. The RPA reaction played a key role to shorten the detection time. However, when the RPA reaction was finished, the addition of SYBR to the RPA reaction mixture needed to be rapid because the RPA reaction is continuous at room temperature; thus, a reaction time of $40 \mathrm{~min}$ or more should be avoided. Furthermore, to detect the single base mutation of EGFR, our newly developed method used both SYBR detection and electrophoresis, and excellent results were obtained within 10 and $20 \mathrm{~min}$.

In addition, other research groups have explored the MutS [18,19,27] protein or PNA probe [28] to reduce the background DNA amplification in LAMP or the PCR method. In the current study, we tried the MutS protein (Gene check Inc., Fort Collins, CO, USA) to prevent background amplification of the single base mutation in the RPA reaction, but the data were ambiguous and the reason is unclear. Furthermore, the use of the RPA reaction to detect the EGFR mutation has been reported by end-point fluorescence detection, lateral flow strips, or microfluidic chips [29-31], but there is no report thus far showing this ARPS system.

However, our currently described novel method does have some limitations; for example, for each EGFR mutation, we need to optimize the methodology to obtain specificity and sensitivity, while each EGFR mutation also needs a specific primer set. Furthermore, our current study only assessed a limited number of clinical tissue samples, and more cases should be assessed in a future study for association with the clinical outcome of EGFR tyrosine kinase therapy. Although the sensitivity of ARPS is relatively lower than other methods, the setup of ARPS is very simple and easy. We could detect EGFR mutations within $15 \mathrm{~min}$, and the specificity was robust without non-targeted sequence amplification. The unique primer design, background suppression technology, and $37^{\circ} \mathrm{C}$ isothermal nature of this assay could provide a practical way for bedside usage or POCT in molecular diagnosis. Our newly developed ARPS method is useful to detect EGFR mutations, especially in un- or underdeveloped regions and countries because such areas may not have instrumentation for DNA sequencing and purification procedures are not required to detect the products.

\section{Materials and Methods}

\subsection{Cell Lines and Culture}

The human non-small cell lung cancer cell lines NCI-H1975, HCC-827, and A-549 were obtained from the American Type Culture Collection (Manassas, VA, USA) and maintained in RPMI-1640 
medium (Gibco, Gaithersburg, MD, USA) supplemented with $10 \%$ fetal bovine serum (HyClone, Logan, UT, USA), $100 \mathrm{U} / \mathrm{mL}$ penicillin, and $100 \mathrm{U} / \mathrm{mL}$ streptomycin at $37^{\circ} \mathrm{C}$ in a humidified incubator containing 5\% $\mathrm{CO}_{2}$ and $95 \%$ air. NCI-H1975 cells harbor the EGFR exon 21 L858R point mutation, HCC-827 cells harbor the EGFR exon19 deletion(2), and A-549 cells contain wild-type EGFR with these two-targeted DNA sequences.

\subsection{NSCLC Tissue Samples}

We collected surgical tissue samples from 46 consecutive patients who were treated at the Second Hospital of Dalian Medical University (Dalian, China) in 2015. All patients were diagnosed with NSCLC according to the International Association for the Study of Lung Cancer lung cancer staging protocol [32]. This study was approved by the Second Hospital of Dalian Medical University, and a written informed consent form was obtained from each patient before participating in this study. Of these 46 patients, 10 cases were subsequently treated with gefitinib. This cohort of patients included 25 females and 21 males with an age at diagnosis ranging from 42 to 87 years old (median of 66 years old). After surgical resection, all tumor samples were immediately snap-frozen and stored at $-80^{\circ} \mathrm{C}$ until use.

\subsection{Genomic DNA Extraction and Detection of EGFR Mutations Using PCR and DNA Sequencing}

Genomic DNA was extracted from NCI-H1975, HCC-827, and A-549 cells as well as patient tissues using DNAiso Reagent (Takara, Dalian, China), according to the manufacturer's instructions. The DNA concentrations were measured using the 260/280 ratio obtained with a spectrophotometer and adjusted to $150 \mathrm{ng} / \mu \mathrm{L}$. The samples were stored at $-20^{\circ} \mathrm{C}$ until use.

Detection of EGFR mutations in these three NSCLC cell lines and tissue samples was performed by PCR amplification with a PCR amplification kit (TransGen, Beijing, China), followed by DNA sequencing. The primers for amplification of EGFR 19Del(2) and L858R regions were the same as described in our previous study (Table 2). The PCR mixtures contained $2 \mu \mathrm{L}$ of genomic DNA, $1 \mu \mathrm{L}$ of each primer $(100 \mu \mathrm{M}), 25 \mu \mathrm{L}$ of $2 \times$ EasyTaq ${ }^{\circledR} \mathrm{PCR}$ Supermix, and $21 \mu \mathrm{L}$ of $\mathrm{ddH}_{2} \mathrm{O}$; the thermal cycling conditions were set to an initial denaturation step at $94{ }^{\circ} \mathrm{C}$ for 5 min and then 30 cycles of $94{ }^{\circ} \mathrm{C}$ for $30 \mathrm{~s}, 55^{\circ} \mathrm{C}$ for $30 \mathrm{~s}$, and $72^{\circ} \mathrm{C}$ for $20 \mathrm{~s}$, and a final extension at $72{ }^{\circ} \mathrm{C}$ for $5 \mathrm{~min}$. The PCR products were then sequenced by using an ABI PRISM 3730 Genetic Analyzer ${ }^{\circledR}$ (ABI, Austin, TX, USA), and the data were analyzed by using ABI PRISM SeqScape Software Version 5.2.0 ${ }^{\circledR}$ (ABI, Austin, TX, USA). The experiments were repeated three times.

Table 2. PCR primers used to detect EGFR mutations

\begin{tabular}{l}
$\frac{\text { EGFR Mutation Type Primers Amplicon (bp) }}{}$ \\
19Del FP 5'-AACGTCTTCCTTCTCTCTCTGTCA-3' 135(Mut)/150(Wild) \\
19Del RP 5'-CCACACAGCAAAGCAGAAACT-3' \\
L858R FP 5'-CTGAATTCGGATGCAGAGCTT-3' 291 \\
L858R RP 5'-CTAGTGGGAAGGCAGCCTGGT-3' \\
\hline FP: Forward Primer, RP:
\end{tabular}

FP: Forward Primer, RP: Reverse Primer, Mut: mutation type, Wild: wild type.

\subsection{The Novel Technique to Detect EGFR Mutations}

Principle of RPA Primer Design

RPA primers were designed according to the instrument guide and principles, i.e., primer length of 30-35 bases and preferred amplicons of $80-400 \mathrm{bp}$ long. In addition, the $3^{\prime}$-primer end for both the forward and the reverse primers should avoid the third codon genome, although it would be fine for $5^{\prime}$-primers. 
To distinguish the mutated sequence from the wild-type one, we designed primers with the help of ASA/AS theory. For the EGFR 19Del(2) mutation, we removed the deleted $15 \mathrm{bp}$ from the forward primer and tried to make the missing portion near the primer $3^{\prime}$-end. For the EGFR L858R mutation, we put the single mutated base at the $3^{\prime}$-end of the reverse primer and added an additional mismatch (another three dNTPs) two bases from its $3^{\prime}$-end. The specificity of these primer sequences was confirmed by alignment to the human genome database using BLAST.

\subsection{Probe Design with PNA to Prevent Non-Target Sequence Amplification}

We designed a probe using the peptide nucleic acid from Beijing Search Co., Ltd. (Beijing, China), which is a type of polypeptide skeleton instead of the main chain of the sugar phosphate DNA analogues. Compared to the same sequence of DNA primers, PNA-DNAs have a stronger binding force and a higher melting temperature, and PNA cannot be detected by SYBR Green I, even under UV light. Thus, we added PNA to combine with the non-target sequence as a probe, ensuring that the RPA could only amplify the mutated sequence. The melting temperature value of the designed PNA probe was found at the web site [33].

\subsection{Biosensor SYBR Green I}

SYBR Green I (Beijing Solarbio Science and Technology Co., Ltd., Beijing, China) is a cost-effective molecular probe to detect double-stranded or single-stranded DNA during PCR amplification. When the level of the DNA products passes the threshold level, the prescribed concentration of SYBR would turn from the original orange color to green as visualized by the naked eye.

\subsection{ARPS Reactions}

For EGFR 19Del(2), a total volume of $50 \mu \mathrm{L}$ of RPA mixture containing $12 \mu \mathrm{L}$ of tri-distilled water, $2 \mu \mathrm{L}$ of each forward and reverse primer, $2 \mu \mathrm{L}$ (300 ng, corresponding to the SYBR detection mechanism) of genomic DNA, and $29.5 \mu \mathrm{L}$ of rehydration buffer was mixed and added with a freeze-dried reagent pellet from the TwistAmp ${ }^{\circledR}$ (TwistDX, Cambridge, UK) basic kit. The mixture was thoroughly vortexed and then added with $2.5 \mu \mathrm{L}$ of $280 \mathrm{mM}$ magnesium acetate solution.

For EGFR L858R, the only difference in SNP amplification was the PNA combining process, i.e., the ARPS reaction contained $10 \mu \mathrm{L}$ of tri-distilled water, $2 \mu \mathrm{L}$ of PNA, and $2 \mu \mathrm{L}$ of genomic DNA in the Eppendorf tube (the PNA concentration was twice that of the primer concentration). The combining process was set to $99^{\circ} \mathrm{C}$ for $2 \mathrm{~min}$ and $66^{\circ} \mathrm{C}$ for $2 \mathrm{~min}$. The primers, the rehydration buffer, amplification enzymes, and magnesium acetate solution were then added to the reaction, accordingly, the same as those of EGFR 19Del(2).

\subsection{Agarose Gel Electrophoresis of RPA Products}

After the RPA reaction was completed, we purified the products using two methods, i.e., (i) A purification column (EasyPure ${ }^{\circledR}$ PCR purification Kit) and (ii) Use of ethanol to remove the RPA reaction buffer. For the purification column method, the DNA extraction procedure was performed according to the manufacturer's protocol (TransGen Biotech, Beijing, China). For the ethanol method, $30 \mu \mathrm{L}$ of the RPA product was added to $100 \mu \mathrm{L}$ of $99.8 \%$ ethanol and centrifuged at $12,000 \mathrm{rpm}$ for $5 \mathrm{~min}$. Next, the supernatant was discarded, and this procedure was repeated twice to purify the RPA products. After that, $30 \mu \mathrm{L}$ of tri-distilled water was added to the tube for agarose gel electrophoresis in a $1.5 \%$ gel.

\subsection{Assessment of Specificity and Sensitivity of the ARPS Assay for EGFR Mutations}

The specificity of the RPA detection assay was assessed by using the DNA extracted from the non-EGFR mutated A549 cell line and the target-mutated HCC-827 and H1975 cell lines, with the EGFR 19Del(2) and EGFR L858R mutations, respectively. Specifically, $300 \mathrm{ng}$ of genomic DNA was 
used to be consistent with SYBR detection color rendering. After the RPA reactions were complete, $30 \mu \mathrm{L}$ of the product was added into a new 1.5-mL Eppendorf tube, and then $1 \mu \mathrm{L}$ of $200 \times$ SYBR was added to the remaining $20 \mu \mathrm{L}$ of product within $1 \mathrm{~min}$ to prevent the RPA reaction from continuing. After the other $30 \mu \mathrm{L}$ of product was purified using the ethanol method, agarose gel electrophoresis was conducted to confirm the band position.

\subsection{Quality Control}

We utilized the control from the TwistAmp ${ }^{\circledR}$ basic kit (TwistDx Inc., Cambridge, UK) for the cell line quality control, and the expected product size was $143 \mathrm{bp}$ (TwistAmp ${ }^{\circledR}$ ). For the tissue samples, genomic DNA from cell lines with known positive and negative EGFR mutations was used as controls.

Supplementary Materials: Supplementary materials can be found at http://www.mdpi.com/1422-0067/17/5/ $792 / \mathrm{s} 1$.

Acknowledgments: This work was supported in part by grants from the National Natural Science Foundation of China (\#91129733 and \#81330060), National High Technology Research and Development Program (863 Research Projects) of China (\#2015AA020409), and the Opening Project of Zhejiang Provincial Top Key Discipline of Clinical Medicine. (No. LKFyc05).

Author Contributions: Yuanbin Liu and Yanbin Kuang conceived, designed, and performed the experiments; Ting Lei and Zhiyu Liu contributed materials and tools; Yuanbin Liu wrote the paper; Jianxin Lyu and Qi Wang gave us guidances and advices.

Conflicts of Interest: The authors declare no conflict of interest.

\section{References}

1. Castillo, L.; Etienne-Grimaldi, M.C.; Fischel, J.L.; Formento, P.; Magne, N.; Milano, G. Pharmacological background of EGFR targeting. Ann. Oncol. 2004, 15, 1007-1012. [CrossRef] [PubMed]

2. Woodburn, J.R. The epidermal growth factor receptor and its inhibition in cancer therapy. Pharmacol. Ther. 1999, 82, 241-250. [CrossRef]

3. Salomon, D.S.; Brandt, R.; Ciardiello, F.; Normanno, N. Epidermal growth factor-related peptides and their receptors in human malignancies. Crit. Rev. Oncol. Hematol. 1995, 19, 183-232. [CrossRef]

4. Paez, J.G.; Jänne, P.A.; Lee, J.C.; Tracy, S.; Greulich, H.; Gabriel, S.; Herman, P.; Kaye, F.J.; Lindeman, N.; Boggon, T.J.; et al. EGFR mutations in lung cancer: correlation with clinical response to gefitinib therapy. Science 2004, 304, 1497-1500. [CrossRef] [PubMed]

5. Lynch, T.J.; Bell, D.W.; Sordella, R.; Gurubhagavatula, S.; Okimoto, R.A.; Brannigan, B.W.; Harris, P.L.; Haserlat, S.M.; Supko, J.G.; Haluska, F.G.; et al. Activating mutations in the epidermal growth factor receptor underlying responsiveness of non-small-cell lung cancer to gefitinib. N. Engl. J. Med. 2004, 350, 2129-2139. [CrossRef] [PubMed]

6. Pao, W.; Miller, V.; Zakowski, M.; Doherty, J.; Politi, K.; Sarkaria, I.; Singh, B.; Heelan, R.; Rush, V.; Fulton, L.; et al. EGF receptor gene mutations are common in lung cancers from "never smokers" and are associated with sensitivity of tumors to gefitinib and erlotinib. Proc. Natl. Acad. Sci. USA 2004, 101, 13306-13311. [CrossRef] [PubMed]

7. Sharma, S.V.; Bell, D.W.; Settleman, J.; Haber, D.A. Epidermal growth factor receptor mutations in lung cancer. Nat. Rev. Cancer 2007, 7, 169-181. [CrossRef] [PubMed]

8. Sordella, R.; Bell, D.W.; Haber, D.A.; Settleman, J. Gefitinib-sensitizing EGFR mutations in lung cancer activate anti-apoptotic pathways. Science 2004, 305, 1163167. [CrossRef] [PubMed]

9. Califano, R.; Abidin, A.Z.; Peck, R.; Faivre-Finn, C.; Lorigan, P. Management of small cell lung cancer: recent developments for optimal care. Drugs 2012, 72, 471-490. [CrossRef] [PubMed]

10. Marchetti, A.; Martella, C.; Felicioni, L.; Barassi, F.; Salvatore, S.; Chella, A.; Camplese, P.P.; Iarussi, T.; Mucilli, F.; Mezzetti, A.; et al. EGFR mutations in non-small-cell lung cancer: Analysis of a large series of cases and development of a rapid and sensitive method for diagnostic screening with potential implications on pharmacologic treatment. J. Clin. Oncol. 2005, 23, 857-865. [CrossRef] [PubMed] 
11. Asano, H.; Toyooka, S.; Tokumo, M.; Ichimura, K.; Aoe, K.; Ito, S.; Tsukuda, K.; Ouchida, M.; Aoe, M.; Katayama, H.; et al. Detection of EGFR gene mutation in lung cancer by mutant-enriched polymerase chain reaction assay. Clin. Cancer Res. 2006, 12, 43-48. [CrossRef] [PubMed]

12. Oshita, F.; Matsukuma, S.; Yoshihara, M.; Sakuma, Y.; Ohgane, N.; Kameda, Y.; Saito, H.; Yamada, K.; Tsuchiya, E.; Miyagi, Y. Novel heteroduplex method using small cytology specimens with a remarkably high success rate for analysing EGFR gene mutations with a significant correlation to gefitinib efficacy in non-small-cell lung cancer. Br. J. Cancer 2006, 95, 1070-1075. [CrossRef] [PubMed]

13. Jänne, P.A.; Borras, A.M.; Kuang, Y.; Rogers, A.M.; Joshi, V.A.; Liyanage, H.; Lindeman, N.; Lee, J.C.; Halmos, B.; Maher, E.A.; et al. A rapid and sensitive enzymatic method for epidermal growth factor receptor mutation screening. Clin. Cancer Res. 2006, 12, 751-758. [CrossRef] [PubMed]

14. Compton, J. Nucleic acid sequence-based amplification. Nature 1991, 350, 91-92. [CrossRef] [PubMed]

15. Notomi, T.; Okayama, H.; Masubuchi, H.; Yonekawa, T.; Watanabe, K.; Amino, N.; Hase, T. Loop-mediated isothermal amplification of DNA. Nucleic Acids Res. 2000, 28, E63. [CrossRef] [PubMed]

16. Gusev, Y.; Sparkowski, J.; Raghunathan, A.; Ferguson, H., Jr.; Montano, J.; Bogdan, N.; Schweitzer, B.; Wiltshire, S.; Kingsmore, S.F.; Maltzman, W.; et al. Rolling circle amplification: A new approach to increase sensitivity for immunohistochemistry and flow cytometry. Am. J. Pathol. 2001, 159, 63-69. [CrossRef]

17. Vincent, M.; Xu, Y.; Kong, H. Helicase-dependent isothermal DNA amplification. EMBO Rep. 2004, 5, 795-800. [CrossRef] [PubMed]

18. Hoshi, K.; Takakura, H.; Mitani, Y.; Tatsumi, K.; Momiyama, N.; Ichikawa, Y.; Togo, S.; Miyagi, T.; Kawai, Y.; Kogo, Y.; et al. Rapid detection of epidermal growth factor receptor mutations in lung cancer by the Smart-Amplification Process. Clin. Cancer Res. 2007, 13, 4974-4983. [CrossRef] [PubMed]

19. Mitani, Y.; Lezhava, A.; Kawai, Y.; Kikuchi, T.; Oguchi-Katayama, A.; Kogo, Y.; Itoh, M.; Miyagi, T.; Takakura, H.; Hoshi, K.; et al. Rapid SNP diagnostics using asymmetric isothermal amplification and a new mismatch-suppression technology. Nat. Methods 2007, 4, 257-262. [CrossRef] [PubMed]

20. Piepenburg, O.; Williams, C.H.; Stemple, D.L.; Armes, N.A. DNA detection using recombination proteins. PLoS Biol. 2006, 4, e204. [CrossRef] [PubMed]

21. Del Río, J.S.; Yehia Adly, N.; Acero-Sánchez, J.L.; Henry, O.Y.; O'Sullivan, C.K. Electrochemical detection of Francisella tularensis genomic DNA using solid-phase recombinase polymerase amplification. Biosens Bioelectron. 2014, 54, 674-678. [CrossRef] [PubMed]

22. Boyle, D.S.; Lehman, D.A.; Lillis, L.; Peterson, D.; Singhal, M.; Armes, N.; Parker, M.; Piepenburg, O.; Overbaugh, J. Rapid detection of HIV-1 proviral DNA for early infant diagnosis using recombinase polymerase amplification. MBio 2013, 4, e00135-13. [CrossRef] [PubMed]

23. Euler, M.; Wang, Y.; Heidenreich, D.; Patel, P.; Strohmeier, O.; Hakenberg, S.; Niedrig, M.; Hufert, F.T.; Weidmann, M. Development of a panel of recombinase polymerase amplification assays for detection of biothreat agents. J. Clin. Microbiol. 2013, 51, 1110-1117. [CrossRef] [PubMed]

24. Newton, C.R.; Graham, A.; Heptinstall, L.E.; Powell, S.J.; Summers, C.; Kalsheker, N.; Smith, J.C.; Markham, A.F. Analysis of any point mutation in DNA. The amplification refractory mutation system (ARMS). Nucleic Acids Res. 1989, 17, 2503-2516. [CrossRef] [PubMed]

25. Collins, F.S.; Varmus, H. A new initiative on precision medicine. N. Engl. J. Med. 2015, 372, $793-795$. [CrossRef] [PubMed]

26. Zhou, D.; Guo, J.; Xu, L.; Gao, S.; Lin, Q.; Wu, Q.; Wu, L.; Que, Y. Establishment and application of a loop-mediated isothermal amplification(LAMP) system for detection of cry1Actransgenic sugarcane. Sci. Rep. 2014, 4, 4912. [PubMed]

27. Wagner, R.; Debbie, P.; Radman, M. Mutation detection using immobilized mismatch binding protein (MutS). Nucleic Acids Res. 1995, 23, 3944-3948. [CrossRef] [PubMed]

28. Tatsumi, K.; Mitani, Y.; Watanabe, J.; Takakura, H.; Hoshi, K.; Kawai, Y.; Kikuchi, T.; Kogo, Y.; Oguchi-Katayama, A.; Tomaru, Y.; et al. Rapid screening assay for KRAS mutations by the modified smart amplification process. J. Mol. Diagn. 2008, 10, 520-526. [CrossRef] [PubMed]

29. Daher, R.K.; Stewart, G.; Boissinot, M.; Bergeron, M.G. Isothermal recombinase polymerase amplification assay applied to the detection of group B streptococci invaginal/anal samples. Clin Chem. 2014, 60, 660-666. [CrossRef] [PubMed] 
30. Crannell, Z.A.; Cabada, M.M.; Castellanos-Gonzalez, A.; Irani, A.; White, A.C.; Richards-Kortum, R. Recombinase polymerase amplification-based assay to diagnose Giardia in stool samples. Am. J. Trop. Med. Hyg. 2015, 92, 583-587. [CrossRef] [PubMed]

31. Lutz, S.; Weber, P.; Focke, M.; Faltin, B.; Hoffmann, J.; Müller, C.; Mark, D.; Roth, G.; Munday, P.; Armes, N.; et al. Microfluidic lab-on-a-foil for nucleic acid analysis based on isothermal recombinase polymerase amplification(RPA). Lab. Chip. 2010, 10, 887-893. [CrossRef] [PubMed]

32. Goldstraw, P.; Crowley, J.; Chansky, K.; Giroux, D.J.; Groome, P.A.; Rami-Porta, R.; Postmus, P.E.; Rusch, V.; Sobin, L.; et al. The IASLC lung cancer staging project: Proposals for the revision of the TNM stage groupings in the forth coming (seventh) edition of the TNM classification of malignant tumours. J. Thorac Oncol 2007, 2, 706-714. [CrossRef] [PubMed]

33. PNA Design Web. Available online: http://www6.appliedbiosystems.com/support/pnadesigner.cfm (accessed on 1 March 2016).

(C) 2016 by the authors; licensee MDPI, Basel, Switzerland. This article is an open access article distributed under the terms and conditions of the Creative Commons Attribution (CC-BY) license (http://creativecommons.org/licenses/by/4.0/). 